\title{
Breaking down Silos through Authentic Assessment: a Live Case Analysis
}

\author{
Olivia Freeman, Rosie Hand, Aileen Kennedy
}

College of Business, Technological University Dublin, Ireland.

\begin{abstract}
One of the aims of Technological University Dublin (TU Dublin) is to create graduates who problem solve as socially responsible global citizens. We wanted to provide an opportunity for our students to address relevant, marketing and consumption challenges in new and innovative ways, and to develop analytical competences and professional skills and comportment in a real-life context. This paper describes the design, implementation and outcome of an inter-disciplinary and cross-programme 'authentic assessment' method which we have termed a 'live case analysis'. The assessment comprised fieldwork, wider industry engagement, formative assessment components and a summative presentation. The method is discussed against the backdrop of a Curriculum Framework project which is underpinned by four design principles which centre around innovation, application, collaboration and flexibility. The performance of real-world tasks such as live case analysis strongly reflects the central pedagogical values of what, where and how people will learn at TU Dublin in the future.
\end{abstract}

Keywords: Authentic Assessment; Live Case Analysis; Curriculum Framework; Formative Assessment; Real-world Application. 


\section{Introduction}

This paper describes the design, implementation and outcome of an inter-disciplinary and cross-programme 'authentic assessment' method which was developed and carried out in response to a rapidly changing learning and teaching environment and a new institutional context. The assessment comprised a live case analysis for a national tourist attraction 'Tayto Park'. Assessment components included fieldwork, industry engagement, formative assessment components and a summative presentation to the senior marketing team and theme park owner. The assessment is discussed against the backdrop of a Curriculum Framework project Co-Create (Collaborative Curriculum Reimagining and Enhancement Aiming to Transform Education) established in TU Dublin, and currently being designed and developed by a team of teaching fellows.

The relevant institutional context is complex and evolving. Ireland's first Technological University was formed from the merger of three Institutes of Technology in January 2019. TU Dublin, engages 28,000 students in research-informed, practice-led education across a range of disciplines from apprenticeships to PhDs. The strategic intent of this newly created institution is to deliver excellence in student centered learning through collaboration and engagement with students, the University and stakeholders from industry, the professions and wider society.

Curriculum is defined as the articulation of the university's values and principles with regards to teaching, learning and assessment, knowledge and the disciplines, and the cultural and political purposes of higher education (https://cocreatetudublin.wordpress.com/). A framework is an overarching scaffolding that influences the manner in which this articulation is approached. The curriculum framework emerges from the pre-existing values and strengths deemed most relevant to nurture, develop and enhance learning into the future. Four design principles have been developed to articulate how the final curriculum framework might shape what, where and how people learn at TU Dublin.

- Step forward and try new things

- Make our learning experience active, useful and related to the world (of work)

- Use our talents; everyone has something to learn and something to teach

- Create the space and time to do work that matters

In this paper we map our assessment innovation, a live business case analysis, against these design principles to frame our discussion and explore the ways in which this innovation reflects the pedagogical tenets encapsulated in the framework. 


\section{Step forward to try new things}

The framework seeks to design in opportunities for evaluation and adaptation of the curriculum to allow innovation to flourish. De Vries' (2018) 'semi permeable curriculum' is open-ended and flexible with regard to content and is borne from a cognizance that faculties of higher education must develop professionals for an, as yet, undefined future. Hughes and Tan (2012) argue for a curriculum which is 'future-sensitive' and adaptable to change in work and society, as well as flexible in relation to diverse cohorts of learners and stakeholders. Stepping forward and trying new things is an appeal to the academic community within the university to try out new ways of doing things, share what works and why innovation matters.

We are three colleagues delivering two modules, namely Marketing, and Consumption, Culture and Markets taught across two postgraduate programmes. This assessment design grew out of our wish to leverage an experiential and authentic learning process for our students which emphasized an application to practice, critical thinking and the development of communication skills. In essence, we wanted our integrated assessment to develop students as holistic, strategic problem solvers. An additional but significant impetus in designing this inter-disciplinary, cross programme assessment was to acknowledge the growing convergence between the disciplines of Marketing and Consumption, Culture and Markets (Parsons, Maclaren and Chatzidakis, 2017).

Authentic assessment (Mueller, 2005) is not a new approach within business education but there is a dearth of empirical research on authentic assessments in business disciplines in general (Sotiriadou, Logan, Daly and Guest, 2019, p.14) and particularly in formal learning environments as opposed to work placements (Ashford-Rowe, Herrington and Brown, 2014). Mueller (2005) reflects Wiggins (1993) in his definition of authentic assessment as a form of assessment in which students are asked to perform real-world tasks that demonstrate meaningful application of essential knowledge and skills.

Ashford Rowe et al. (2014) build on Gulikers, Bastiaens and Kirschner's (2004) work in their development of an eight principle framework and suggest that for an assessment to qualify as authentic it should be challenging, include a crafted outcome, foster the development of transferable knowledge, allow for self-reflection, simulate and measure a real-world test of ability, include formally designed opportunities for feedback and opportunities to collaborate.

The live case analysis assessment described in more detail in the next section of this paper qualifies as 'authentic' across these eight criteria. The development of the assessment fits with the curriculum design principle 'Step forward to try new things'. The inter-disciplinary cross programme live case assessment described in detail in the next section of the paper emerged as a result of, and as a response to, the changing theoretical and policy contexts in which learners and educators collaborate. The succesful implementation of this assessment 
points to the import of this curriculum design principle for our university in the current higher education climate.

\section{Make our learning experience active, useful and related to the world (of work)}

The second design principle of the curriculum framework speaks to the substance and quality of learning experiences. Technological innovation coupled with demand from employers and government for a more highly skilled workforce have resulted in changes in relation to the ways higher education is mediated and accessed (Ashford-Rowe, Herrington and Brown, 2014). Existing modes of assessment need to be critiqued in the context of this changing terrain. Meyers and Nulty (2009, p.567) posit that in order to encourage deep learning, academics must provide tasks and experiences which are (i) authentic, real-world and relevant, (ii) constructive and interlinked, (iii) command higher order processing from students, (iv) aligned with each other and the desired learning outcomes, and (v) provide challenge and motivation to learn.

We wanted to provide an opportunity for our students to address relevant, real marketing and consumption challenges in new and innovative ways, and to develop analytical competences and professional skills and comportment in a real-life context. Having broadly reviewed the Irish brandscape for potential collaborators we enlisted Tayto Park as a client/partner for our live case analysis.

Tayto Park is one of Ireland's top ten fee-charging attractions and it is a unique mix of theme park, activity centre, zoo, and educational facility. The idea for the theme park was inspired by similar parks in the US, such as Hershey Park in Pennsylvania, which has grown to become a major tourist attraction. The business opened to the public in October 2010 and recorded attendance figures of 330,422 in its first full year of trading in 2011 and that number had grown to 770,000 in 2018. Tayto Park recorded profits of $€ 3.1 \mathrm{~m}$ in 2017 , up from $€ 2.9 \mathrm{~m}$ the previous year, on sales of $€ 17.5 \mathrm{~m}$. A significant majority of visitors are families with children under the age of twelve, drawn from Dublin and surrounding counties. Seventy five percent of visitor numbers are recorded between July and August each year, with footfall averaging 10-11,000 per day, depending on the weather. It is the ambition of the management team to target one million visitors by 2021 .

The Tayto Park brand story was elicited from the Marketing Director over the course of a face-to-face meeting. From this, a detailed, live case study was crafted. The case comprised a theoretical backdrop incorporating marketing theory and consumption theory relevant to the brand, a detailed brand contextualisation and an outline of the challenges facing the brand. Specific questions were designed to actively engage the learners in immersive problemsolving. The questions are replicated below: 
- Discuss the expectations, concerns, and desires families experience as they engage in planning 'a day out'?

- What brand attributes are currently being communicated by Tayto Park?

- Should Tayto Park continue to use the Tayto brand name? Argue for or against this strategy.

- Outline your key strategic marketing recommendations for Tayto Park over the next 5 years.

The live case analysis described here demonstrates the potential to create meaningful industry and employment-related assessment for full-time post-graduate students and provides an exemplar of what is envisaged by the mantra 'Make our learning experience active useful and related to the world of work'.

\section{Use our talents; everyone has something to learn and something to teach}

The third design principle of the curriculum framework calls for celebration of the opportunity's university life presents for collaboration between and among students, educators and partners. The live case analysis assessment described in this paper is an example of the type of student-educator-partner collaboration that sees people bring their unique talents and perspectives together to produce something tangible, dynamic and ripe for ongoing revision as the learning process is not a linear one. The curriculum framework provides support for authentic assessment and in so doing endorses Brew's (2013) contention that 'universities should become scholarly knowledge-building communities where academics and students work together to learn and solve problems of the world' (p.609).

Linked to this call is the need to breakdown existing silos between disciplines, promote inclusion and diversity of the university community and to think beyond summative assessments as a key success measure of teaching and learning (National Forum, 2017). This live case assessment fostered collaboration amongst the teaching team, breaking down disciplinary silos, while achieving a collective goal. It also promoted the integration of international students from eight countries and embraced a number of students registered with disability and learning support services at TU Dublin.

Meyers and Nulty (2009) argue assessment plays a pivotal role in curriculum design and acknowledge that an appropriate assessment task serves to underpin student learning, encourages student engagement with the associated learning resources and leads to attainment of the desired learning outcomes. The Irish National Framework of Qualifications states that programmatic learning outcomes at postgraduate level require learners to demonstrate higher order thinking (https://nfq.qqi.ie). In this live case analysis, we endeavored to build an assessment which allowed us evaluate four key learning outcomes (two from each module) designed to develop the requisite competencies. These learning 
outcomes required the learner to (i) apply theory to analyse and develop responses to consumption-based issues in business and societal contexts, (ii) identify and apply advanced marketing techniques and frameworks for problem solving, (iii) formulate strategic responses to marketing challenges and finally (iv) be able to communicate and present advanced ideas competently.

Incorporating students from diverse undergraduate backgrounds ensured breadth and variety of perspectives was a contributory factor in fostering collaboration and engendering a climate of inclusion between and amongst students. In line with Asford Rowe et al.'s (2014) eight principle framework students were encouraged to actively engage with every stage of the assessment process across one semester. In order to achieve an immersive experience, students participated in a formal site visit to the theme park and meet members of the senior management team for a $\mathrm{Q}$ and $\mathrm{A}$ session. A two-stage formative assessment process followed the field visit and these collaborative meetings allowed learners to receive constructive formal feedback on their work to date. During stage one students conducted a guided literature search to inform a phase of primary research. In response, we assessed the quality and relevance of their chosen theoretical underpinnings. Stage two involved us meeting with each group to approve their research strategy and effectively 'greenlighting' them to move on to the research implementation stage. An industry expert from a global experiential brand was invited as a guest lecturer to give students a wider context within which to consider their Tayto Park challenge. At the end of the semester, student groups presented their case solutions to the Tayto Park senior management team, their lecturers and peers.

Mueller (2005) argues that good assessments of any type begins with meaningful goals and standards. We developed a rubric (Reddy and Andrade, 2010) which comprised five evaluative criteria along with performance level descriptions that described what 'instantiations of those criteria look like in work at varying quality levels, from low to high' (Brookhart, 2018, p.1). Criteria included depth of engagement in relation to research design and implementation, quality of insights generated, quality of strategic and tactical recommendations made, and, competence in relation to delivery of oral presentation and documentation. Students received the rubric in advance of commencing the task to enhance understanding around lecturer expectations regarding the completed assessment. Eight groups of six participated in this assessment. The overall average score was $66 \%$ with a top score of $77 \%$ and a lowest performing score of $51 \%$.

We used peer group performance appraisal (Topping, 2009) to encourage students to take responsibility for their own learning, help them reflect on their contribution to the assessment, mitigate against social loafing behavior, and, importantly, allow them to appraise the performance of their group members (Wanner and Palmer, 2018). Performance appraisal is a critical work-related skill which dovetails with the stated objectives of authentic 
assessment. The senior management team at Tayto Park remarked that deep insights had been uncovered and commented on the professionalism displayed.

\section{Create the space and time to do work that matters}

Priestley and Philippou's (2019, p.2) vision of curricula argue for learner-centred approaches, active pedagogies and facilitation of learning by educators. The final design principle articulated by the Co-Create team centres on the creation of time and space to do work that matters. Encouragement for innovation in teaching, learning and assessment, specifically provision for staff to upskill in the area of authentic assessment is pertinent to creating a learner-centred approach. We received the encouragement and support of our leadership team in a number of crucial ways. In order to be innovative we needed to invest more time and flexibility than that typically associated with a traditional assessment method. We were provided with resources to enable students to take part in a client site visit. We were afforded appropriate physical spaces depending on our needs including the use of an executive suite for the final presentations. The Learning, Teaching and Technology Centre (LTTC) in TU Dublin provided many opportunities for us to pursue continuing professional development. We are grateful for these supports many of which are encapsulated by Sotiriadou et al. (2019) as essential.

The overall experience of engaging with authentic assessment was a positive one. Students achieved the required learning outcomes, as demonstrated, for example, by the evidence of higher order-thinking in strategic responses to the live brief. We acknowledge some of the challenges this assignment presented for students including time-management, anxiety around presentations and group dynamics. Peer assessment provided a structured learning process for students to critique and provide feedback to each other, and developed skills to manage group conflict and dynamics. We helped the students navigate problems arising and utilised formative assessment and informal class discussion to check-in on student progress observing the development of important transferable skills. A particular advantage of this kind of assessment is the clear sense of ownership that students developed around their ideas and how their confidence built. Collaboration, teamwork, and empathy are designated TU Dublin graduate attributes and are considered highly desirable in the workplace.

\section{Conclusion}

The performance of real-world tasks in the academic environment is deemed reflective of the pedagogical values encapsulated in the emergent curriculum framework as envisaged by the Co-Create teaching fellowship team for TU Dublin. This paper describes the design, development and implementation of a 'live case analysis' for students across two Masters level business programmes. This 'authentic assessment' has been described in the context of 
the four key design principles of the curriculum framework project; innovation, application, collaboration and flexibility and in so doing we have illustrated the value of a curriculum framework in helping to shape and support the development of meaningful authentic engagement between students, educators and wider societal entities.

\section{References}

Ashford-Rowe, K., Herrington, J. \& Brown, C. (2014). Establishing the critical elements that determine authentic assessment, Assessment \& Evaluation in Higher Education, 39(2), 205-222.

Brew, A. (2013). Understanding the scope of undergraduate research: a framework for curricular and pedagogical decision-making. Higher Education, 66, 603-618.

Brookhart, S. M. (2018). Appropriate criteria: Key to effective rubrics. Frontiers in Education, 3, 22.

Co-CREATE Project website https://cocreatetudublin.wordpress.com/

de Vries, Bregje, et al. (2018). Exploring the concept of a semi-permeable curriculum: Mixed Audience Masterclasses in teacher education. Journal of Finnish Universities of Applied Sciences 3.

Gulikers, J. T., Bastiaens, T. J., \& Kirschner, P. A. (2004). A five-dimensional framework for authentic assessment. Educational technology research and development, 52(3), 67.

Hughes, J. \& Tan, E. (2012). The Dynamic Curriculum: Sharing Experiences of Ongoing Curricular Change in Higher Education. Dublin: DRHEA.

Meyers, N. M., and D. D. Nulty. 2009. "How to use (five) curriculum design principles to align authentic learning environments, assessment, students' approaches to thinking and learning Outcomes."Assessment \& Evaluation in Higher Education 34(5), 565-577.

Mueller, J. (2005). The authentic assessment toolbox: enhancing student learning through online faculty development. Journal of Online Learning and Teaching, 1(1), 1-7.

National Forum for the Enhancement of Teaching and Learning in Higher Education, "Authentic Assessment in Irish Higher Education," in teachingandlearning.ie, Published March 30, 2017, Last Accessed January 17, 2020, https://www.teachingandlearning.ie/publication/authentic-assessment-in-irishhigher-education/

Parsons, E., Macalaren, P., \& Chatzidakis, A., (2017) Contemporary Issues in Marketing and Consumer Behaviour, 2nd Edition. London:Routledge.

Priestley, M. \& Philippou, S. (2019). Curriculum is - or should be - at the heart of educational practice. The Curriculum Journal, 30 (1), 1-7.

Reddy, Y. M., \& Andrade, H. (2010). A review of rubric use in higher education. Assessment and Evaluation in Higher Education, 35(4), 435-448.

Sotiriadou, P., Logan, D., Daly, A., \& Guest, R. (2019). The role of authentic assessment to preserve academic integrity and promote skill development and employability. Studies in Higher Education, 1-17.

Topping, K. J. (2009). Peer assessment. Theory into practice, 48(1), 20-27. 
Wanner, T., \& Palmer, E. (2018). Formative self-and peer assessment for improved student learning: the crucial factors of design, teacher participation and feedback. Assessment \& Evaluation in Higher Education, 43(7), 1032-1047.

Wiggins, G.P. (1993). Assessing Student Performance. San Francisco: Jossey-Bass Publishers. 